dose administered at 9 am for 1 week, performance was measured by number of math problems completed correctly, teacher-recorded on-task behavior and noncompliance, and Abbreviated Conners Teacher Rating Scale. Tests were completed immediately and beginning 2, 4, and 6 hours after drug ingestion. Beneficial effects of pemoline on classroom behavior and academic performance were linear, beginning 2 hours after ingestion and lasting at least 7 hours. Side effects during observation were minimal, and response was comparable to that reported in studies of methylphenidate. (Pelham WE Jr et al. Pemoline effects on children with ADHD: A time-response by dose-response analysis on classroom measures. IAm Acad Child Adolesc Psychiatry November 1995;34:1504-1513). (Reprints: Dr Pelham. Western Psychiatric Institute and Clinic, 3811 O'Hara Street, Pittsburgh, PA 15213).

COMMENT. The commonly held belief that response to pemoline is gradual and sometimes delayed for 3 or 4 weeks was contradicted by the results of this study that demonstrate an acute beneficial effect, comparable to that of methylphenidate. The authors recommend that doses of pemoline higher than 18.75 or $37.5 \mathrm{mg}$ may be needed for optimal benefit, and a prolonged response may be expected after a single morning dose. The side-effect of insomnia, reported in $32 \%$ of patients in one previous long-term trial, could not be evaluated in the present study because parent and sleep evaluations were not included. In my own patients with a complaint of sleep disturbance during treatment with pemoline, the side-effect was reported soon after initiation of therapy, suggesting a more acute onset of response than that noted in the manufacturer's reports. The present study confirms the need to consider increments of dosage more rapidly than recommended in the PDR.

\title{
ADVERSE FAMILY-ENVIRONMENT FACTORS AND ADHD
}

The influence of exposure to parental psychopathology and conflict on functioning and comorbidity in 140 children with ADHD and 120 normal controls was studied at the Pediatric Psychopharmacology Unit in Psychiatry, Massachusetts General Hospital and Harvard Medical School, Boston. Increased levels of environmental adversity were found among ADHD compared with control probands for all adversity variables and especially for parental conflict, diminished family cohesion, number of parents with psychiatric illness, and time exposed to maternal psychopathology $(\mathrm{p}<.01)$. Superior IQ protected ADHD subjects from negative influences of parental psychopathology. The risk of developing comorbidity (conduct disorder, depression, anxiety) in ADHD subjects was not influenced by environmental adversity. (Biederman $\mathrm{J}$ et al. Impact of adversity on functioning and comorbidity in children with attention-deficit hyperactivity disorder. I Am Acad Child Adolesc Psychiatry Nov 1995;34:1495-1503). (Reprints: Dr Biederman, Pediatric Psychopharmacology Unit (ACC 725), Massachusetts General Hospital, 15 Parkman Street, Boston, MA 02114).

COMMENT. Adverse family environments, including chronic family conflict, decreased family cohesion, and exposure to maternal psychopathology, are risk factors in children with ADHD. Early recognition of these environmental factors should lead to intervention and improved outcome. The investigation of children with ADHD is multimodal and requires cooperation between various specialties 
involved. Parents will usually not accept from a neurologist the reality of their own behavior as a factor in the child's disorder. The expertise of a psychologist or psychiatrist is required when parental conflict is suspected.

\section{MILD HEAD INJURY AND COGNITIVE DEFICIT}

The effect of mild head injury in 78 preschool children on their cognitive performance, especially reading ability, evaluated one year after injury and at 6.5 years of age was investigated at the Department of Neurosurgery, Auckland Hospital, New Zealand. Compared to a control group with minor injury not involving the head, head injured preschoolers showed impairment of interpretation of visual puzzles, a visual closure test, and increased incidence of reading difficulties at 6 and 12 months after injury and at age 6.5 years. Another head injury occurred within 6 months in $14 \%$ of the head injured group compared to $<1 \%$ of the control group. Reading ability was correlated with the scores on visual closure at one year after injury. (Wrightson P et al. Mild head injury in preschool children: evidence that it can be associated with a persisting cognitive defect. I Neurol Neurosurg Psychiatry October 1995;59:375-380). (Respond: Mr Philip Wrightson, 18 Crocus Place, Remuera, Auckland 1005, New Zealand).

COMMENT. Mild head injury, not sufficient to require admission for observation, may result in cognitive deficits and impairment of reading and school performance. In this study, the development of visual skills necessary for reading appeared to be interrupted by the injury.

In a previous report reviewed in Progress in Pediatric Neurology I, (PNB Publishers, 1991, p408), mild head injury in 114 school aged children did not have an adverse effect on global measures of cognition and achievement at one to five years after injury. Children with head injuries were indistinguishable from uninjured children on all tests except the teachers' report of hyperactivity which was $4 / 10$ of a standard deviation higher. (Bijur PE et al. Pediatrics 1990;86:337). Hyperactivity noted after head injury might be significant and worthy of careful follow-up and management.

\section{BRAIN NEOPLASMS}

\section{MIGRAINE EPISODES FOLLOWING CRANIAL IRRADIATION}

Complicated migraine-like episodes occurring 1.2 to 2.8 years after cranial irradiation and chemotherapy for brain tumor are reported in four children treated at the Children's National Medical Center, Washington, DC. Three had neuroectodermal tumors and one an ependymoma in the posterior fossa. Headaches lasted 2 to 24 hours and were intermittent, unilateral, and associated with nausea, visual loss, hemiparesis, aphasia, or hemisensory loss. MRIs were unchanged, and CSF, EEGs, EKGs, and MR angiograms were normal. Cerebral angiograms in 3 children were normal but caused recurrence of temporary migraine-like episodes complicated by delirium. Response to propranolol and aspirin was good in 1 and partial in 3. (Shuper A, Packer RJ et al. 'Complicated migraine-like episodes' in children following cranial irradiation and chemotherapy. Neurology Oct 1995;45:1837-1840). (Reprints: Dr Roger J Packer, Department of Neurology, Children's National Medical Center, 111 Michigan Ave, NW, Washington, DC 20010). 